\title{
PRESENÇA DE HELMINTOS POTENCIALMENTE ZOONÓTICOS EM AMOSTRAS FECAIS AMBIENTAIS EM PRAÇAS DE JAGUARÃO (RS), BRASIL
}

\author{
EVARISTO, Tainá Ança ${ }^{1}$; \\ FERRAZ, Alexsander ${ }^{2}$; \\ ANTUNES, Tatiana de Ávila ${ }^{1}$; \\ MARTINS, Natália Soares ${ }^{3}$; \\ PAPPEN, Felipe Geraldo ${ }^{5}$; \\ MUELLER, Alice ${ }^{1}$; \\ LIGNON, Júlia Somavilla ${ }^{4}$; \\ PINTO, Diego Moscarelli ${ }^{5}$.
}

objetivo deste trabalho foi analisar a presença de parasitos com potencial zoonótico, em amostras de fezes, coletadas de duas praças do município de Jaguarão (RS). As coletas foram realizadas mensalmente, de agosto de 2016 a agosto de 2017. Em cada coleta, foram recolhidas três amostras de fezes de cada uma das praças, totalizando 78 amostras. As fezes foram processadas pelo método de Willis-Mollay. Do total de amostras (78), 55 apresentaram-se positivas para pelo menos um gênero de parasito, representando $70,51 \%$ do total. 0 parasito observado em maior frequência foi o Ancylostoma spp., presente em 51 amostras (65,38\%). Os meses que apresentaram maior frequência de contaminação foram fevereiro e julho de 2017, com 100\% das amostras positivas. Conforme os resultados obtidos, conclui-se que existe contaminação por Ancylostoma spp., Trichuris spp. e Toxocara spp. em praças da cidade de Jaguarão, Rio Grande do Sul.

Palavras-chave: Zoonoses. Cães. Helmintos. Contaminação. 


\section{INTRODUÇÃO}

A proximidade humana com os pets pode levar ao aumento nas taxas de contaminação por zoonoses, colocando a saúde do tutor em risco (GURGEL et al., 2005). Os animais domiciliados, com programa de vermifugação inadequado, bem como os animais que possuem acesso à rua e cães errantes, que transitam livremente em praças e praias, são potenciais disseminadores de parasitos no meio ambiente (AMARAL et al., 2015).

De acordo com Neves et al. (2011), a doença parasitária é consequência de um desequilíbrio entre o hospedeiro e o agente parasitário, e seu espectro pode variar conforme o número de formas infectantes, a capacidade de causar doença (de acordo com a imunidade do hospedeiro), idade, nutrição, estado corporal de uma forma geral e os órgãos afetados.

Zoonoses são enfermidades transmitidas naturalmente dos animais ao homem. Apesar dos avanços verificados no seu controle, a incidência de zoonoses permanece alta em todos os países em desenvolvimento (ANDRADE et al., 2002). Em municípios com baixo índice de desenvolvimento humano (IDH), estima-se prevalência de 2 a 36\% de geo-helmintoses (BRASIL, 2012).

Na maioria dos municípios brasileiros é comum encontrar um grande número de cães errantes circulando em locais de lazer, como praças. Grande parte desses animais não possuem um tutor ou proprietário, tampouco recebem cuidados básicos, como controle de endoparasitos, dessa forma, tornam-se uma fonte de contaminação para os centros urbanos (FUCHS et al., 2011).

Os principais helmintos com importância em saúde pública, causadores de zoonoses, no Brasil são: Ancylostoma spp., Toxocara spp. e Trichuris spp., também chamados de geohelmintos, dado que uma fase de seu ciclo ocorre no solo (IYABO; OLUCHI, 2015).

A ancilostomíase canina é definida como uma infecção gastrointestinal. O cão contamina-se pela ingestão dos ovos ou pela penetração ativa da larva do parasito através da epiderme. A migração do Ancylostoma spp. causa, no cão, principalmente diarreia e anemia, pela característica de hematofagia do agente, porém em baixas infecções pode permanecer assintomático (NUNES et al., 2000). Os ovos do parasito são eliminados junto com as fezes 
do hospedeiro no ambiente e, em condições adequadas, eclodem, liberando a larva, que na forma de L3 é infectante. Nos cães, a localização preferencial deste parasita é o intestino delgado, no homem, a larva penetra ativamente através da pele, fazendo migrações no tecido subcutâneo, sendo denominada Larva Migrans Cutânea (LMC), popularmente chamada de bicho-geográfico. No hospedeiro acidental (homem) pode produzir erupções serpinginosas na pele, lesões granulomatosas e intenso prurido (LIMA, 2011).

O ascarídeo Toxocara spp. infecta principalmente filhotes, através da transmissão fecal-oral, transplacentária ou transmamária. Uma vez ingerido pelo hospedeiro, o parasito pode permanecer na forma de cisto tecidual. No caso de uma fêmea gestante, a imunodepressão, que se estabelece no periparto, permite que larvas encistadas nos tecidos da mãe atinjam os fetos por via transplacentária, essa transmissão vertical é possível mesmo que a mãe não tenha sido infectada recentemente (LIMA, 2011).

A toxocaríase humana (Larva Migrans Visceral) acomete o homem através da ingestão dos ovos embrionados de Toxocara spp., as larvas eclodem no intestino delgado, penetram a mucosa e invadem o sistema porta. Algumas larvas se encistam no fígado, mas outras atingem os pulmões e o sistema circulatório (CAPUANO; ROCHA, 2006). Em casos mais graves podem migrar até a porção ocular, levando ao quadro denominado de Larva Migrans Ocular (LMO) (HOLLAND; SMITH, 2006).

O clima tropical e subtropical possui condições favoráveis para diversos parasitas, como Trichuris spp. Apesar de apresentar ampla distribuição, há maior ocorrência em regiões com clima quente e úmido, associado a níveis sanitários precários, aumentando a sobrevivência dos ovos e manutenção do ciclo do parasito (BIASI et al., 2010; NEVES et al., 2011).

Lima et al. (2010) definem como promoção e educação em saúde, parte de princípios e práticas que visam estratégias relevantes para tecnificar procedimentos enfocados exclusivamente na redução da ocorrência de doenças zoonóticas, como as parasitárias. Visando, desta forma, o que a Organização Mundial da Saúde (OMS, 2003) define como saúde: estado pleno de desenvolvimento mental, físico e de bem-estar social.

É de grande importância, especialmente em países em desenvolvimento, a educação sanitária da população e a adoção, por parte das autoridades públicas, de medidas e práticas 
de saúde pública, capazes de minimizar os transtornos causados pelas zoonoses, objetivando a prevenção, o controle e até mesmo a erradicação dessas enfermidades (PERIAGO, 2004).

O presente estudo teve como objetivo relatar a ocorrência de parasitoses com potencialidade zoonótica em amostras de fezes recolhidas de praças públicas no município de Jaguarão, Rio Grande do Sul, Brasil.

\section{MATERIAL E MÉTODOS}

Mensalmente, seis amostras fecais de cães foram coletadas de duas praças públicas do município de Jaguarão (RS), três amostras provenientes de cada praça. De forma aleatória, no período de agosto de 2016 a agosto de 2017, 78 amostras foram coletadas.

As amostras frescas foram coletadas do ambiente a cada 30 dias, no período da tarde, de três pontos equidistantes em plano horizontal da praça pública. A presença de cães errantes no ambiente, no momento das coletas, era obrigatória. A mesma metodologia foi mantida durante todo o experimento.

As amostras foram armazenadas em recipientes isotérmicos, com gelo reutilizável, para manter a integridade do material, sendo encaminhadas para análise coproparasitológica no Laboratório de Parasitologia do Grupo de Estudos em Enfermidades Parasitárias (GEEP) da Faculdade de Medicina Veterinária (FaVet) da Universidade Federal de Pelotas (UFPEL), sendo analisadas no máximo em 48 horas após a coleta.

A técnica de Willis-Mollay (1921) foi utilizada para diagnóstico, através do método de flutuação em solução hipersaturada de glicose, princípio qualitativo, que consiste na flutuação dos ovos de helmintos por diferença de densidade em relação a osmolaridade da solução, avaliando-se a presença ou ausência de ovos de geo-helmintos sob microscopia óptica.

\section{RESULTADOS E DISCUSSÃO}

Das 78 amostras analisadas entre os anos de 2016 e 2017, 55 apresentaram algum gênero parasitário de importância em saúde pública, representando $70,51 \%$ do total. 
Diante dos dados analisados, foi possível verificar maior ocorrência para o nematelminto Ancylostoma spp., observado em 65,38\% (51/78) das amostras, seguido de Trichuris spp. com 15,38\% (12/78) e Toxocara spp. com 3,84\% (3/78).

Em nenhuma das coletas houve ausência de gêneros parasitários nas amostras analisadas, esses dados estão expressos na Tabela 1.

Tabela 1 - Prevalência de gêneros de parasitos zoonóticos em amostras de fezes coletadas entre os meses de agosto de 2016 e agosto de 2017 em duas praças públicas do município de Jaguarão, Rio Grande do Sul.

\begin{tabular}{cccc} 
& \multicolumn{3}{c}{ Gêneros Parasitários } \\
\cline { 2 - 4 } Mês/ano & Ancylostoma spp. (\%) & Trichuris spp. (\%) & Toxocara spp. (\%) \\
\hline Agosto 2016 & 50 & 0 & 33,33 \\
Setembro 2016 & 33,33 & 0 & 0 \\
Outubro 2016 & 33,33 & 0 & 0 \\
Novembro 2016 & 66,67 & 33,33 & 0 \\
Dezembro 2016 & 33,33 & 0 & 0 \\
Janeiro 2017 & 33,33 & 33,33 & 0 \\
Fevereiro 2017 & 100 & 0 & 0 \\
Março 2017 & 83,33 & 16,67 & 0 \\
Abril 2017 & 33,33 & 16,67 & 0 \\
Maio 2017 & 33,33 & 16,67 & 0 \\
Junho 2017 & 83,33 & 16,67 & 16,67 \\
Julho 2017 & 100 & 33,33 & 0 \\
Agosto 2017 & 66,67 & 33,33 & 0 \\
\hline
\end{tabular}

Nos meses de fevereiro e julho de 2017, a presença de ovos de um mesmo gênero de helminto foi constatada em $100 \%$ das amostras coletadas. As fases pré-infectantes, ovos e larvas, de helmintos zoonóticos de animais de companhia desenvolvem-se no ambiente e são dependentes das condições climáticas. Com as temperaturas ótimas variando de 25 a 30 ${ }^{\circ} \mathrm{C}$, porém, em temperaturas mais baixas, como $15{ }^{\circ} \mathrm{C}$, o desenvolvimento não é interrompido, entretanto, torna-se mais lento, ocorrendo com média de 22 dias (SOULSBY, 1987; VIEIRA, 2012). 
Ocorreu múltiplo parasitismo em nove das 78 amostras (11,53\%). Sendo Ancylostoma spp. e Trichuris spp. em sete amostras (8,97\%), Ancylostoma spp. e Toxocara spp. em uma amostra (1,28\%) e Ancylostoma spp., Trichuris spp. e Toxocara spp. também em uma amostra (1,28\%). Demonstrando uma baixa ocorrência de infecções por mais de um agente parasitário zoonótico nas amostras avaliadas. Ferraz et al. (2019), estudando a presença de ovos de parasitos potencialmente zoonóticos em fezes de cães coletadas no entorno de 22 escolas públicas municipais de Pelotas (RS), constataram uma ocorrência mais elevada de parasitismo múltiplo, com 31,53\% das amostras nessa condição (35/111).

É relevante destacar a ocorrência de grande número de ovos de Ancylostoma spp. nas amostras que foram positivas na técnica de Willis-Mollay, conforme Figura 1.
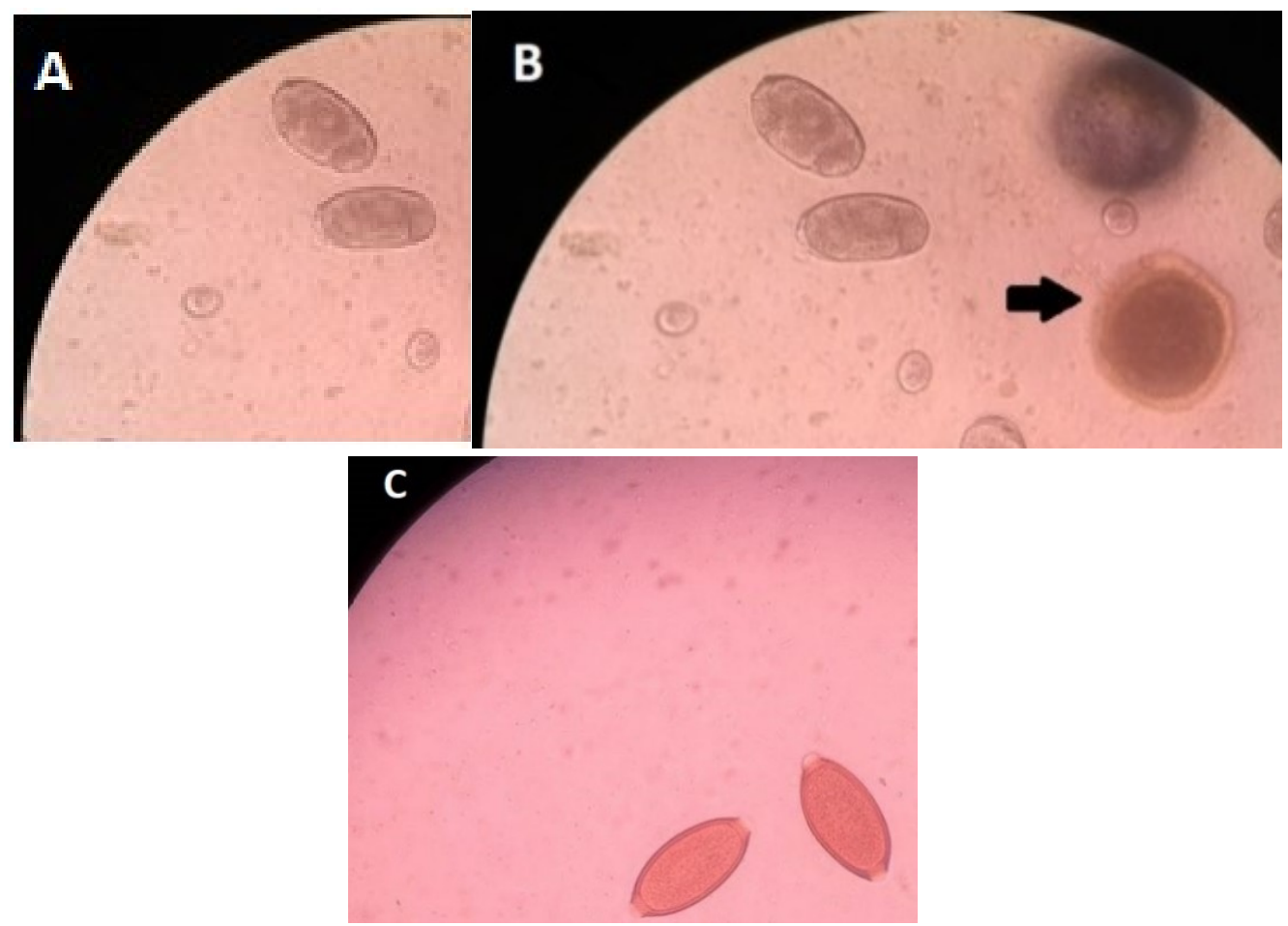

Figura 1 - Identificação morfológica de ovos de helmintos presentes em amostras de fezes recolhidas de duas praças públicas da cidade de Jaguarão, Rio Grande do SUL, sob análise pela técnica coprológica Willis-Mollay. Legenda: (A) - Ovos de Ancylostoma spp. em aumento de 10x em microscopia óptica; (B) - Ovos de Toxocara spp. em aumento de 40x em microscopia óptica; (C) - Ovos de Trichuris spp. com aumento de 40x em microscopia óptica. 
O município de Jaguarão apresenta $61,9 \%$ de domicílios com esgotamento sanitário adequado, incluindo as áreas urbana e rural, ou seja, 38,1\% dos domicílios não possuem saneamento básico apropriado. Além disso, até 2016, a cada mil habitantes, 0,6 foram internados em virtude de quadros clínicos de diarreia, sem causa determinada (IBGE, 2018).

A alta prevalência de ovos de Ancylostoma spp. em amostras fecais coletadas de espaços públicos de lazer, no município de Jaguarão, é preocupante, tendo em vista que esse geohelminto é o agente causal da Larva Migrans Cutânea (LMC) e tem sido apontado como causador de quadros de enterite eosinofílica em humanos (WALKER et al., 1995). É particularmente comum em áreas quentes e úmidas, as quais favorecem o desenvolvimento de ovos e larvas. Em regiões de clima tropical e subtropical, como Jaguarão, este agente zoonótico encontra condições favoráveis para desenvolver toda sua capacidade de disseminação (SCHANTZ, 1994).

Da área central do balneário do Cassino, município do Rio Grande, região sul do Rio Grande do Sul, Scaini et al. (2003) coletaram 237 amostras fecais de cães, no período de março a novembro de 2002 . Verificaram que $86,1 \%$ das amostras foram positivas para ovos ou larvas de helmintos e destas 33,3\% apresentavam contaminação mista. Ovos e larvas de Ancylostoma spp. estavam presentes em $71,3 \%$ das amostras, ovos de Trichuris spp. em 32,5\% e ovos de Toxocara em 9,3\%. Esses resultados demonstram a alta contaminação por agentes potencialmente zoonóticos em áreas públicas de lazer, justificados pela presença de cães domiciliados, peridomiciliados e errantes que contaminam o ambiente com material fecal, especialmente por Ancylostoma spp., numa taxa bastante aproximada a encontrada para este geo-helminto em praças da cidade de Jaguarão.

Em dez praças públicas da cidade de Itabuna, Bahia, Campos Filho et al. (2008), ao analisarem 119 amostras fecais de cães, observaram que 47,9\% estavam contaminadas por ovos de Ancylostoma spp., 4,2\% por Trichuris spp. e 4,2\% por Toxocara spp. Revelando uma elevada prevalência de Ancylostoma spp. em relação aos outros geo-helmintos zoonóticos identificados, assim como foi demonstrado no presente estudo.

Resende et al. (2015), ao analisarem 39 amostras fecais coletadas de 18 praças da cidade de Viçosa (MG), nos meses de abril, maio e junho, encontraram valores inferiores para 
Ancylostoma spp. (18\%) e Trichuris spp. (13\%) e uma maior contaminação por Toxocara spp. (10\%).

Ribeiro et al. (2013), ao avaliarem 30 amostras de solo, colhidas de seis praças da cidade de Esteio, Rio Grande do Sul, encontraram $56,6 \%$ de amostras positivas para formas parasitárias zoonóticas. Sendo que ovos de Ancylostoma spp. estavam presentes em $50 \%$ das amostras $(15 / 30)$.

No município de Valença, Rio de Janeiro, foram analisadas 30 amostras de solo, provenientes de seis praças públicas, para pesquisa de ovos de Ancylostoma spp. e Toxocara spp. Em 30\% (9/30) das amostras de solo, de quatro das seis praças, foi constatada contaminação por ovos de Ancylostoma spp. Nenhuma amostra apresentou ovos de Toxocara spp. (CIRNE et al., 2017).

Segundo Pereira-Cardoso et al. (2010), a inexistência ou deficiência do saneamento básico associada a fatores sociais, econômicos e culturais são determinantes para o estabelecimento de parasitoses intestinais na população infantil. Nesse contexto, é fundamental estabelecer medidas de saúde pública que também contemplem o efetivo controle das zoonoses, de modo especial nos locais de lazer público, onde o risco para as crianças é maior, em razão da contaminação do solo por material fecal de cães e gatos, ao hábito de brincar junto ao solo e a alterações do apetite, como a geofagia, comuns nessa faixa etária (CAPUANO; ROCHA, 2006).

\section{CONCLUSÃO}

Conforme os resultados obtidos, conclui-se que existe contaminação por Ancylostoma spp., Trichuris spp. e Toxocara spp. em praças da cidade de Jaguarão, Rio Grande Sul. A alta prevalência de Ancylostoma spp. nas amostras analisadas recomenda a implementação de medidas sanitárias que impeçam a contaminação dos espaços públicos de lazer por formas parasitárias zoonóticas. 


\title{
PRESENCE OF POTENTIALLY ZOONOTIC HELMINT HS IN ENVIRONMENTAL FECAL SAMPLES IN THE SQUARES OF JAGUARÃO (RS), BRAZIL
}

\begin{abstract}
$\mathrm{T}$ he objective of this work was to analyze the presence of parasites with zoonotic potential, in samples of dog faeces, collected from two squares of Jaguarão city, RS. The collections were carried out monthly, from August 2016 to August 2017. In each collection, three stool samples were collected from each of the squares, totaling 78 samples. The faeces were processed by the method of Willis-Mollay. Of the total samples (78), 55 were positive for at least one genus of parasite, representing $70.51 \%$ of the total. The most frequent parasite was Ancylostoma spp., present in 51 samples (65.38\%). The months that presented the highest frequency of contamination, were February and July 2017 with $100 \%$ of the samples positive. According to the results obtained, it is concluded that there is contamination by Ancylostoma spp., Trichuris spp., and Toxocara spp. in squares in the city of Jaguarão, Rio Grande do Sul.
\end{abstract}

Keywords: Zoonosis. Dogs. Helminths. Contamination.

\section{PRESENCIA DE HELMINTOS POTENCIALMENTE ZOONÓTICOS EN MUESTRAS FECALES AMBIENTALES EN JAGUARÃO (RS), BRASIL}

\section{RESUMEN}

$\mathrm{E}$ objetivo de este trabajo fue analizar la presencia de parásitos con potencial zoonótico, en muestras de heces de perros, recogidas de dos plazas del municipio de Jaguarão, RS. Las colectas fueron realizadas mensualmente, de agosto de 2016 a agosto de 2017. En cada colecta, fueron recogidas tres muestras de heces de cada una de las plazas, totalizando 78 muestras. Las heces fueron procesadas por el método de WillisMollay. Del total de muestras (78), 55 fueron positivas para al menos un género de parásito, representando el $70,51 \%$ del total. El parásito encontrado en mayor frecuencia fue el Ancylostoma spp., presente en 51 muestras (65,38\%). Los meses que presentaron mayor frecuencia de contaminación, fueron febrero y julio de 2017 con el $100 \%$ de las muestras positivas. De acuerdo con los resultados obtenidos, se concluye que existe contaminación por Ancylostoma spp., Trichuris spp. y Toxocara spp. en plazas de la ciudad de Jaguarão, Rio Grande do Sul.

Palabras clave: Zoonosis. Perros. Helmintos. Contaminación. 


\section{REFERÊNCIAS}

AMARAL, L. S.; DUARTE, A. N.; SILVA, V. L.; et al. Parasitological indicators of contamination at sand of beaches and monitoring by traditional methods and immunoenzymatic assay.

Revista Brasileira de Engenharia de Biossistemas, v. 9, n. 4, p. 304-311, 2015.

ANDRADE, A.; PINTO, S. C.; OLIVEIRA, R. S. Animais de Laboratório: criação e experimentação. Rio de Janeiro: Fiocruz, 2002. 388p.

BIASI, L. A.; TACCA, J. A.; NAVARINI, M.; et al. Prevalência de enteroparasitoses em crianças de entidade assistencial de Erechim/RS. Revista Perspectiva, v. 34, n. 125, p. 173-179, 2010.

BRASIL. Secretaria de Vigilância em Saúde. Departamento de Vigilância das Doenças Transmissíveis. Plano integrado de ações estratégicas de eliminação da hanseníase, filariose, esquistossomose e oncocercose como problema de saúde pública, tracoma como causa de cegueira e controle das geohelmintíases: plano de ação 2011-2015. Brasília: Ministério da Saúde, 2012. 100p.

CAMPOS FILHO, P. C.; BARROS, L. M.; CAMPOS, J. O.; et al. Parasitas zoonóticos em fezes de cães em praças públicas do município de Itabuna, Bahia, Brasil. Revista Brasileira de Parasitologia Veterinária, v. 17, n. 4, p. 206-209, 2008.

CAPUANO, D. M.; ROCHA, G. M. Ocorrência de parasitas com potencial zoonótico em fezes de cães coletadas em áreas públicas do município de Ribeirão Preto, SP, Brasil. Revista Brasileira de Epidemiologia, v. 9, n. 1, p. 81-86, 2006.

CIRNE, F. S. L.; SILVA, T.; CARVALHO, A. C. F.; et al. Contaminação ambiental por ovos de Ancylostoma spp. e Toxocara spp. em áreas de seis praças públicas do município de Valença, estado do Rio de Janeiro. Acta Biomedica Brasiliensia, v. 8, n. 1, p. 35-38, 2017.

FERRAZ, A.; PIRES, B. S.; SANTOS, E. M.; EVARISTO, T. A.; LEÃO, M. S.; MELLO, C. C. S.; CASTRO, T. A.; PINTO, D. M.; NIZOLI, L. Q. Ocorrência de parasitos gastrintestinais de cães, com potencial zoonótico no entorno de escolas municipais de educação infantil de Pelotas, RS, Brasil. Revista de Ciência Veterinária e Saúde Pública, v. 6, n. 2., p. 291-301, 2019.

FUCHS, T.; PEDRASSANI, D.; BRANCO, R. Helmintos em áreas de lazer de centros de educação infantil do município de Canoinhas, Santa Catarina. Ágora: revista de divulgação científica, v. 18, n. 1, p. 163-176, 2011.

GURGEL, R. G.; CARDOSO, G. S.; SILVA, A. M.; et al. Creche: ambiente expositor ou protetor nas infestações por parasitas intestinais em Aracaju, SE. Revista da Sociedade Brasileira de Medicina Tropical, v. 38, n. 3, p. 267-269, 2005.

HOLLAND, C. V.; SMITH, H. V. Toxocara: the enigmatic parasite. Cambridge: Cabi Publishing, 2006. 301p. 
IBGE - INSTITUTO BRASILEIRO DE GEOGRAFIA E ESTATÍSTICA. Jaguarão - Panorama. Disponível em: <https://cidades.ibge.gov.br/brasil/rs/jaguarao/panorama> .

IYABO, U. B.; OLUCHI, U. R. Geohelminth contamination of common fruits and vegetables in Ebonyi State, Nigeria: the public health implication. AASCIT Journal of Bioscience, v. 1, n. 2, p. 15-19, 2015.

LIMA, A. M. A.; ALVES, L. C.; FAUSTINO, M. A. G.; et al. Percepção sobre o conhecimento e profilaxia das zoonoses e posse responsável em pais de alunos do pré-escolar de escolas situadas na comunidade localizada no bairro de Dois Irmãos, na cidade do Recife (PE). Ciência \& Saúde Coletiva, v. 15, supl. 1, p. 1457-1464, 2010.

LIMA, W. S. Larva migrans. In: NEVES, D. P.; MELO, A. L.; LENARDI, P. M.; et al. Parasitologia humana. 12. ed. São Paulo: Atheneu, 2011. P. 291-294.

NEVES, D. P. MELO, A. L.; LENARDI, P. M.; et al. Parasitologia humana. 12. ed. São Paulo: Atheneu, 2011, 546p.

NUNES, C. M.; PENA, F. C.; NEGRELLI, G. B.; et al. Ocorrência de larva migrans na areia de áreas de lazer das escolas municipais de ensino infantil, Araçatuba, SP, Brasil. Revista de Saúde Pública, v. 34, n. 6, p. 656-658, 2000.

OMS - ORGANIZAÇÃO MUNDIAL DA SAÚDE. CIF - Classificação Internacional de Funcionalidade, Incapacidade e Saúde. OMS, 2003. 216p. Disponível em: <http://biblioteca.cofen.gov.br/wp-content/uploads/2014/10/cif_portugues.pdf> .

PEREIRA-CARDOSO, F. D.; ARAÚJO, B. M.; BATISTA, H. L.; et al. Prevalência de enteroparasitoses em escolares de 06 a 14 anos no município de Araguaína-Tocantins. Revista Eletrônica de Farmácia, v. 7, n. 1, p. 54-64, 2010.

PERIAGO, M. R. Zoonosis y enfermedades transmisibles comunes al hombre y a los animales. Revista do Instituto de Medicina Tropical de São Paulo, v. 46, n. 5, p. 278, 2004.

RESENDE, A. P. M.; MOREIRA, L. M. S.; PINTO, R.; et al. Incidência de endoparasitos de caráter zoonótico em locais públicos na cidade de Viçosa, Minas Gerais. Revista Científica Univiçosa, v. 7, n. 1, p. 417-424, 2015.

RIBEIRO, K. L.; FREITAS, T. D.; TEIXEIRA, M. C.; et al. Avaliação da ocorrência de formas parasitárias no solo de praças do município de Esteio (RS). Revista Acadêmica: Ciências Agrárias e Ambientais, v. 11, n. 1, p. 59-64, 2013. 
SCAINI, C. J.; TOLEDO, R. N.; LOVATEL, R. M.; et al. Contaminação ambiental por ovos e larvas de helmintos em fezes de cães na área central do Balneário Cassino, Rio Grande do Sul. Revista da Sociedade Brasileira de Medicina Tropical, v. 36, n. 5, p. 617-619, 2003.

SCHANTZ, P.M. Parasitic zoonoses in perspective. International Journal of Parasitology, v. 21, n. 2, p. 161-170, 1991.

SOULSBY, E. J. L. Parasitología y enfermedades parasitarias em los animales domésticos. 7. ed. México: Nueva Editorial Interamericana, 1987. 823p.

VIEIRA, V. S. F. Avaliação do desenvolvimento de ovos de Ancylostoma caninum e Trichuris vulpis submetidos à baixas temperaturas e infecção experimental com Trichuris vulpis em cães. Seropédica, UFRRJ, 2012. 101p. Dissertação (Mestrado em Ciências Veterinárias), Programa de Pós-Graduação em Ciências Veterinárias, Instituto de Veterinária, Universidade Federal Rural do Rio de Janeiro, 2012.

WALKER, N. I.; CROESE, J.; CLOUSTON, A. D.; et al. Eosinophilic enteritis in northeastern Australia. Pathology, association with Ancylostoma caninum, and implications. The American Journal of Surgical Pathology, v. 19, n. 3, p. 328-337, 1995.

WILLIS-MOLLAY, H. H. A simple levitation method for the detection of hookworm ova. The Medical Journal of Australia. v. 2, n. 18, p. 375-376, 1921.

Autor para correspondência: Diego Moscarelli Pinto. Departamento de Veterinária Preventiva, Faculdade de Veterinária, Universidade Federal de Pelotas, Campus Universitário, prédio 1, 2ªndar, Capão do Leão (RS), CEP 96160-000. dimoscarelli@yahoo.com.br 